\title{
Occlusal magic...
}

Occlusion and its many

side issues can be very seductive, to the extent

that quite amazing

claims for medical cures

have been made by

some of the proponents

of occlusal therapy
$\mathbf{T}$

This issue of the $B D J$ sees the start of a new clinical series, 'A Clinical Guide to Occlusion' by Stephen Davies et al. The subject of occlusion is still shrouded in confusion and debate, and this series is designed to provide a 'working philosophy' (my emphasis) for practising dentists, cutting through the haze of opinion as often as possible to provide sensible guidelines supported by the latest evidence.

I have to admit to a personal interest in the topic, as occlusion fascinated me as a dental student. At dental school I was taught of its importance, but given no practical help as to what to do about occlusal discrepancies in my patients. In fact, I am not even sure I knew what occlusal discrepancies were back then. It seemed to me that dental school stressed the importance of getting the occlusion right when I was carrying out treatment, but singularly failed to help me understand what to do when patients arrived with an occlusion that had started out 'wrong' before I saw them.

As Robert Jagger points out in his introduction to the new series on page 233 of this issue I sought answers to my own lack of knowledge in postgraduate courses and from various self-proclaimed experts. As his introduction also points out this resulted in even more confusion for me because the experts did not agree, despite the fact that all of them claimed to be right. I resisted the temptation to believe that the more expensive the course the more accurate the information, and also succeeded in resisting the many attempts to sell me articulators (all designed differently depending on the expert), preferring the trusty Dentatus I was familiar with from dental school. Eventually, armed with a little knowledge and a lot of enthusiasm I set out to conquer the world of occlusal disease I was convinced (at that time) surrounded me on all sides.

I regret that, for a while, I fell under the 'occlusal spell' that sometimes grips dentists who follow the path I was travelling. I came to believe occlusion was far more important than I now believe it is, seeing occlusal problems where perhaps there were none. Thankfully I was following a very conservative approach to occlusal therapy, fitting various splints to 'relax the musculature' rather than adjusting the enamel or (even worse) fitting restorations to create the 'ideal' occlusion. If only I had known then the principles explained by David and Gray (in this issue) when I was struggling to find my own way, things would have been so much easier.

Despite my ignorance I saw dramatic results with some patients who experienced quite substantive improvements. This initially reinforced my belief in the importance of occlusion, but I was perplexed because in other patients there was no apparent benefit. I began questioning some of the dogma, especially some of the more unusual claims that were made. Occlusion and its many side issues can be very seductive, to the extent that quite amazing claims for medical cures have been made by some of the proponents of occlusal therapy. I am glad now that I treated these with caution as I could have so easily been swayed by the charismatic rhetoric of some of the occlusal experts and thus started treating my own patients with a lack of responsibility.

My own experiences taught me that occlusion is an important topic and one that every dentist needs to understand. However, the road to understanding is fraught with twists and side alleys that can easily distract, and some of these distractions can potentially (or actually) damage our patients unless we understand the principles behind the treatment of occlusion. The series we are publishing builds from these basic principles, and that is why I am delighted to see it within the pages of the $B D J$. 